\title{
Research on Water Level Control Scheme of Reservoir Flood Resources Utilization Considering Dam Safety and Risk Benefit
}

\author{
Xianfeng Huang ${ }^{1, a}$, Jie Lin ${ }^{1, b}$, Xiaoping Qu ${ }^{1, c}$, Guohua Fang ${ }^{1, d}$, Lixiang Zhu ${ }^{2, e}$ \\ ${ }^{1}$ College of Water Resources and Hydropower Engineering, Hohai University, Nanjing \\ 210098,China \\ ${ }^{2}$ Water Conservancy Bureau of Lianyungang City, Lianyungang 222000, China \\ a18539123@qq.com, b304963786@qq.com, 'c1183918779@qq.com, dhhufgh@126.com, \\ lygzlx@163.com
}

\begin{abstract}
Keywords: Adjustment of limited water level; Multi-objective risk decision model; Sam safety risk rate; Comprehensive risk benefit.

Abstract. The method of using reservoir flood resource based on adjusting flood control level will inevitably bring a risk while generating some economic benefits. How to use the flood resources safely and reasonably needs to carry out risk decision. In this paper, reservoir flood resources utilizations is the target, considering reservoir dam safety and risk-benefit, and building multi-objective risk decision model of the reservoir limited water level adjustment. Comprehensive risk-benefit considerate the benefit of reservoir flood resource utilization and risk loss. The benefit of reservoir flood resource utilization includes three kinds of supply benefits in industry, agriculture and domestic water supply. Risk loss is the damage caused by the dam safety risk. The establishment of decision model should be able to calculate the comprehensive benefit of reservoir flood resources utilization in a dynamic change between the economic benefit and risk loss, to weigh the risk and comprehensive benefit, to determine the best equilibrium value of limited water level. Selecting Shilianghe reservoir as the study case, determining its limited water level of flood resources utilization, the research results provide some references for our country's water level control scheme in the use of reservoir flood resources.
\end{abstract}

\section{Introduction}

As the tense situation of supply and demand of water resources has become a prominent social problem, more and more people are paying attention to non-traditional water-use such as rain, floods, recycled water and brackish water. Flood, as an unconventional resource, a prudent and objective manner must be maintained in the process of utilization, to make use of the water resources under the condition of ensuring the safety of water conservancy projects. To meet the conditions above, it needs to research and analysis the risk of flood resources utilization.

The study abroad started early in the relevant field of control for limited water level. By analyzing the relationship between flood volume and flood control capacity, Loucks (1981) reached the relationship between different flood discharge magnitude and corresponding loss under a certain flood control capacity [1]. Wang (2000) presented a fuzzy optimal control model for Pre-storage level of reservoir, whose objective functions are economic benefit and risk rate [2]. Zhou (2009) proposed a risk decision model for flood control optimization operation of reservoirs, getting possible flood control scheduling scheme by means of a multi-objective flood control optimization scheduling, analyzing risk combined with flood forecasting tolerance, and calculating risk rate of scheduling scheme [3]. Aiming at the shortcomings of the traditional flood risk decision-making evaluation method, based on the thought of Support Vector Machine, Ji (2013) converted the multi-objective decision-making problem with random variables to the preferred issue based on the minimum value of comprehensive risk [4].

At present, the research on dynamic limited flood water level control, urban flood control, flood insurance, flood plain area management and risk decision, has made some achievements. But because of the uncertainty of flood risk and involving many fields of social, economic and ecological environment, there are still many imperfections. The present results are mostly concentrated on the 
research of flood risk analysis method, such as analysis method based on probability theory and mathematical statistics, Monte Carlo stochastic modeling method, limit analysis method. It lacks of study on the theory and method of whole risk management, especially the study on risk decision is relatively less. In view of this, this paper intends to build a multi-objective risk decision model for adjusting limited water level of reservoir, which is applied to flood resources of Shilianghe reservoir so as to find the optimal equilibrium scheme of limited water level adjustment.

\section{Construction and solution of risk decision-making model for adjusting limited water level}

The building of risk decision-making model targets minimizing risk rate and maximizing overall economic benefits. Among them, comprehensive risk-benefit considerate benefit of flood resources utilization and risk loss. The benefit of flood resources utilization includes three kinds of supply water benefit in industry, agriculture and domestic water supply. Risk loss is the damage caused by the dam safety risk.

\section{Target of Dam Safety Risk Rate}

Due to the probability density function of dam safety accident being difficult to determine, it is impossible to establish integral equations to calculate risk rate. But statistically calculating the historical flood data and integrating dam safety risk probability density function are on the same principle, by which the dam safety risk rate can be obtained [5]. The formula is as follows:

$$
\min f_{1}\left(H_{i}\right)=\frac{n}{N+1}
$$

where, $f_{1}\left(H_{i}\right)$ is the risk rate when limited water level is $H_{\mathrm{i}}$ and design standard level is overtaken; $N$ is the total number of data series in previous floods; Under the given flood control level $H_{\mathrm{i}} ; n$ is the flood frequency when water level exceeds the design standards level $Z_{\mathrm{d}}$ by flood routing.

\section{Target of Comprehensive Risk Benefit}

After adjusting limited water level, comprehensive risk benefit mainly reflect in production and living benefit that can be played by increasing the storage of reservoir water, and deducting the risk loss brought by adjustment of limited water level. The formula is as follows:

$$
\max f_{2}\left(H_{i}\right)=\sum_{j=1}^{n} B_{j}\left(H_{i}\right)-\sum_{j=1}^{m} L_{j}\left(H_{i}\right)
$$

where, $f_{2}\left(H_{i}\right)$ is the overall risk-benefit value when flood control level is $H_{i} ; B_{j}\left(H_{i}\right)$ is the benefit of flood resources utilization when flood control level is $H_{i}, L_{j}\left(H_{i}\right)$ is the risk loss when limited water level is $H_{i} ; n, m$ are the numbers of benefit and risk loss.

\section{Case Study}

Shilianghe reservoir is the key project of diverting water from east to south in Yishusi rivers basin. As the largest reservoir in Jiangsu Province, it is located in the junction of Donghai county and Ganyu county, neighboring Linshu county, Shandong province to the west, and about $35 \mathrm{~km}$ to Lianyungang city to the east. The reservoir undertake releasing runoff between upstream of Xinshu river, Yi river and Shu river, catchment area of about $15365 \mathrm{~km}^{2}$, total storage capacity of 531 million $\mathrm{m}^{3}$. The reservoir was built in 1958. A hydroelectric power station was constructed in 1970, and installed 7 sets and total capacity of $1120 \mathrm{~kW}$. It was designed by a hundred year frequency flood, and checked by 2000 year frequency, with design flood level $26.81 \mathrm{~m}$, check flood level $27.95 \mathrm{~m}$ and maximum discharged 
flow $10131 \mathrm{~m}^{3} / \mathrm{s}$. Shilianghe reservoir undertake the primary function of flood regulation in Yishusi rivers basin, and protecting Lianyungang City against flooding. In addition, Shilianghe reservoir is the second water source of domestic and industrial water in Lianyungang city, which played a huge comprehensive benefit since the completion.

\section{Calculation of the Dam Safety Risk Rate of Shilianghe Reservoir}

The highest level is $26.82 \mathrm{~m}$ that Shilianghe reservoir had ever reached since its run-off, $0.01 \mathrm{~m}$ above the design flood level. In the calculation of dam safety risk rate, design flood level $26.81 \mathrm{~m}$ of Shilianghe reservoir is taken as design standard level $Z_{d}$, Performing flood routing on different frequencies of flood to approach or exceed the level, the dam safety risk rate is taken as the flood frequency under flood control level [6]. Through analyzing statistical data of input water from upstream in Shilianghe reservoir, corresponding value of dam safety risk rate under various flood control level shown in Table 1.

Table 1 The dam safety risk rate under different limited water levle

\begin{tabular}{cccc}
\hline Limted water level $(\mathrm{m})$ & Risk rate & Limited water level $(\mathrm{m})$ & Risk rate \\
\hline 23.50 & 0.0153 & 24.50 & 0.0422 \\
\hline 23.60 & 0.0164 & 24.60 & 0.0485 \\
\hline 23.70 & 0.0175 & 24.70 & 0.0532 \\
\hline 23.80 & 0.0185 & 24.80 & 0.0576 \\
\hline 23.90 & 0.0208 & 24.90 & 0.0641 \\
\hline 24.00 & 0.0230 & 25.00 & 0.0770 \\
\hline 24.10 & 0.0252 & 25.10 & 0.0970 \\
\hline 24.20 & 0.0289 & 25.20 & 0.1185 \\
\hline 24.30 & 0.0326 & 25.30 & 0.1401 \\
\hline 24.40 & 0.0363 & & \\
\hline
\end{tabular}

\section{Calculation of the Comprehensive Risk Benefit of Shilianghe Reservoir}

The benefit of flood resources utilization consists agriculture, industry and domestic water supply. According to the statistical yearbook and the official reports on water resources of Lianyungang city in 2013. The allocation proportion of water resources on industry, agriculture and domestic water supply is $32 \%, 64 \%$ and $32 \%$. The distributions of flood resources utilization rate also take the above ones. The first two industrial added value are: $I_{i}=6.548$ billion RMB, $I_{a}=1.24$ billion RMB, and the efficiency of water resources utilization is 0.9 . The allocation coefficients of water benefit are: $f_{i}=0.05$, $f_{a}=0.45, f_{l}=0.3$ [7]. Based on the statistical yearbook of Lianyungang city from 2009 to 2013, the disposable income of residents is $12000 \mathrm{RMB}$. Engel's coefficient is 0.36 , and the per capita water consumption is $593 \mathrm{~m}^{3}$.

The reservoir dam risk loss mainly refers to the loss to the downstream area caused by overtopping or inrush. According to calculation of the dam safety risk rate and the loss value after the disaster happens, the risk loss of flood resources utilization under different limited water level can be computed. Based on the related research, the indirect loss coefficient of flood disaster on agriculture is $15 \%-28 \%$; the same on industry is $16 \%-35 \%$. Considering both, it is taken as $25 \%$. The direct loss per unit area is $720000 \mathrm{RMB} / \mathrm{km}^{2}$, and flooding area is $200 \mathrm{~km}^{2}$. The cost of flood prevention and disaster relief is taken as $15 \%$ of the direct and indirect economic loss.

In combination of the benefit of flood resources utilization and risk loss, the relationship between the comprehensive risk benefit and the limited water level can be obtained. The results of calculation are shown in Table 2. 
Table 2 The calculation of comprehensive risk benefit

\begin{tabular}{cccccccc}
\hline $\begin{array}{c}\text { Limited } \\
\text { water } \\
\text { level }(\mathrm{m})\end{array}$ & $\begin{array}{c}\text { Benefit of } \\
\text { flood } \\
\text { utilization } \\
\left(10^{4} \mathrm{RMB}\right)\end{array}$ & $\begin{array}{c}\text { Risk loss } \\
\left(10^{4} \mathrm{RMB}\right)\end{array}$ & $\begin{array}{c}\text { Comprehensive } \\
\text { risk benefit } \\
\left(10^{4} \mathrm{RMB}\right)\end{array}$ & $\begin{array}{c}\text { Limited } \\
\text { water level } \\
(\mathrm{m})\end{array}$ & $\begin{array}{c}\text { Benefit of } \\
\text { flood } \\
\text { utilization } \\
\left(10^{4} \mathrm{RMB}\right)\end{array}$ & $\begin{array}{c}\text { Risk loss } \\
\left(10^{4} \mathrm{RMB}\right)\end{array}$ & $\begin{array}{c}\text { Comprehensive } \\
\text { risk benefit } \\
\left(10^{4} \mathrm{RMB}\right)\end{array}$ \\
\hline 23.50 & 0.0 & 316.7 & 0.0 & 24.50 & 2148.8 & 873.5 & 2148.8 \\
\hline 23.60 & 203.2 & 339.5 & 203.2 & 24.60 & 2377.8 & 1004.0 & 2377.8 \\
\hline 23.70 & 409.0 & 362.3 & 409.0 & 24.70 & 2609.4 & 1101.2 & 2609.4 \\
\hline 23.80 & 617.4 & 383.0 & 617.4 & 24.80 & 2843.6 & 1192.1 & 2843.6 \\
\hline 23.90 & 828.4 & 430.6 & 828.4 & 24.90 & 3080.4 & 1326.3 & 3080.4 \\
\hline 24.00 & 1042.0 & 476.1 & 1042.0 & 25.00 & 3319.9 & 1593.9 & 3319.9 \\
\hline 24.10 & 1258.3 & 521.6 & 1258.3 & 25.10 & 3561.6 & 2007.9 & 3561.6 \\
\hline 24.20 & 1476.8 & 598.2 & 1476.8 & 25.20 & 3806.3 & 2453.0 & 3806.3 \\
\hline 24.30 & 1698.3 & 674.8 & 1698.3 & 25.30 & 4053.2 & 2900.1 & 4053.2 \\
\hline 24.40 & 1922.0 & 751.4 & 1922.0 & & & & \\
\hline
\end{tabular}

The relationship between comprehensive risk benefit and dam risk rate can be shown in Figure 1.

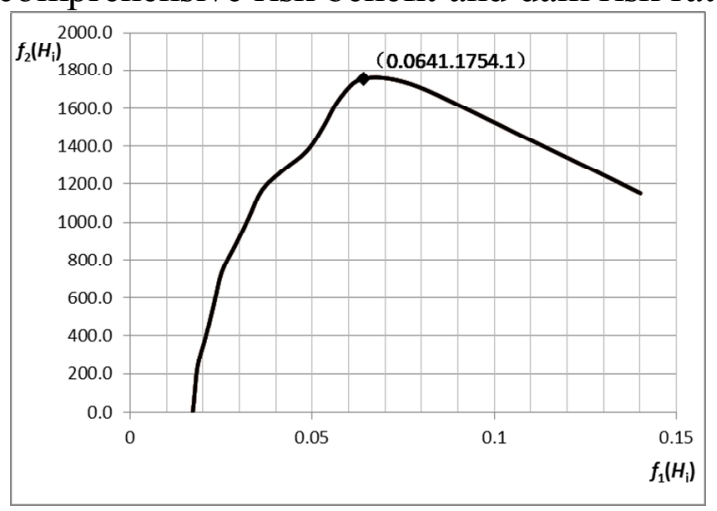

Fig. 1 The curve of the comprehensive risk benefit and the risk rate

\section{The Multi-objective Risk Decision-making Model of Shilianghe Reservoir}

To find the solution, the method of constraint is used in the paper. The risk can be converted to constraint condition: $f_{1}\left(H_{i}\right) \leq \varepsilon_{1}$. In the case of comprehensive risk benefit being positive, the Figure 2 shows that $0.0175 \leq \varepsilon_{1} \leq 0.064$. The number of value is 3 , namely $\varepsilon_{1}=0.0175,0.0422,0.0641$, which gets three Pareto solutions.

The first scheme: the risk rate is 0.0175 , and the corresponding comprehensive risk benefit is 467,000 RMB. The limited water level is $23.7 \mathrm{~m}$, and the capacity of flood storage can be increased by 10.93 million $\mathrm{m}^{3}$.

The second scheme: The risk rate is 0.0422 , and the corresponding comprehensive risk benefit is 12.753 million RMB. The limited water level is $24.5 \mathrm{~m}$, and the capacity of flood storage can be increased by 57.43 million $\mathrm{m}^{3}$.

The third scheme: The risk rate is 0.0641 , and the comprehensive risk benefit is 17.541 million RMB, which is maximum. The limited water level is $24.9 \mathrm{~m}$, and the capacity of flood storage can be increased by 82.33 million $\mathrm{m}^{3}$.

\section{Analysis of Results}

The benefit of flood resources utilization increases with the raise of limited water level, the same as the dam safety risk rate. When the risk rate comes to 0.0641 , the comprehensive risk benefit of 
reservoir is maximum. The comprehensive risk benefit is on the decline if the risk rate continues to increase. The reason is that added value of benefit is less than the added value of loss, causing the comprehensive benefit on the decrease. The calculation of dam safety risk rate is relative to the upstream water of reservoir. When the dam safety risk is at a rate of $10 \%$, the corresponding limited water level of Shilianghe reservoir is $25.1 \mathrm{~m}$. That is to say, if the limited water level is $25.1 \mathrm{~m}$, the flood level of reservoir will reach or exceed the design standard value when the frequency of upstream water is once in a decade, which will have a bad effect on the dam safety. But the security can be guaranteed by increasing discharge of the reservoir. And when the design standard value is set to the design flood level of reservoir, there is a certain capacity of flood storage. While the risk rate is lower than $10 \%$, the risk is thought to be manageable. Through comparing the risk rate of the third scheme is moderate and the relevant comprehensive benefit is maximum, which is an ideal option to utilize the flood resources of reservoir.

\section{Conclusion}

(1) In this paper, the multi-objective risk decision model for adjusting the limited level of reservoir was established. Risk Analysis for adjustment of limited water level in Shilianghe reservoir was studied. The scheme which was the optimum equilibrium adjustment of limited level was found. It greatly improved the utilization rate of flood resources.

(2) When calculating the risk rate of dam safety after adjustment of the limited water level by the probability statistic method, the water level of design standard $Z_{d}$ was the value of design flood level. It is considered that would constitute the dam safety risk, if the water level of flood regulation reaches the design flood level. This is a conservative choice. The water level of design standard $Z_{d}$ still has room to improve under the states that ensure the safety of the dam.

\section{Acknowledgements}

This work was financially supported by the Fundamental Research Funds for the Natural Science Foundation of Jiangsu Province (BK20130849), Water Conservancy Science and Technique of Jiangsu Province (2014064), the Fundamental Research Funds for the Central Universities (2014B25314), and Science and Technique Project of Lianyungang City (SH1429).

\section{References}

[1] D. P. Loucks, J R Stedinger, D A Haith. Water resources systems planning and analysis, New Jersey: Prentie-Hall, 1981.

[2] Wang, B D, Zhou, H C, Cheng, C T, et al, Benefit and Risk Model for Controlling Pre-storage Level of Reservoir, Journal of China Hydrology, Vol. 20, No. 1,pp. 14-18.

[3] Li, Y H, Zhou, J Z, Zhang, Y C, et al, Risk Decision Model for the Optimal Operation of Reservoir Flood Control and Its application, Water Power, Vol. 35, No. 4, 2009, pp. 19-21.

[4] Ji, C M, Li, K F, Zhang, Y K, et al, Multi-objective Risk Decision-making Model for the Joint Operation of Cascade Hydropower Stations, Water Power, Vol. 39, No. 4, 2013, pp. 61-64.

[5] Yan, B W, Guo, S L, Risk Estimation of Reservoir Flood Operation in Consideration of Inflow Hydrograph Forecasting Error, Journal of Hydraulic Engineering, Vol. 43, No. 7, 2012, pp. 803-807.

[6] Shi, G Q, Zhu, H N, Xun, H P, et al, Study on Reservoir Dam-break Loss and Its Calculation Methods, Vol. 13, No. 4, 1998, pp. 28-33. 
[7] Wu, H Y, Diao, X D, Zeng, S X, Analysis of Benefit of Water Diversion From Yangtze River to Taihu Lake: Case Study in Huzhou City, Advances in Water Science, Vol. 19, No. 6, 2008, pp. 888-892. 